\title{
Assessment of Knowledge, Attitude and Practices towards the Disposal of Unused and Expired Medications among Students of Private Medical Universities in Lusaka, Zambia
}

\author{
Martin Kampamba ${ }^{*}$, Vewoerd Maingaila1, Tumelo Muyenga Akapelwa ${ }^{2}$, Steward Mudenda ${ }^{1}$, \\ Luke Biete ${ }^{3}$, Webrod Mufwambi ${ }^{1}$, Michelo Banda ${ }^{1}$, Margaret Phiri' \\ Christabel Nang'andu Hikaambo ${ }^{1}$ \\ ${ }^{1}$ Department of Pharmacy, School of Health Sciences, University of Zambia, Lusaka, Zambia \\ ${ }^{2}$ Department of Physiological Sciences, School of Medicine and Health Sciences, Mulungushi University, Livingstone, Zambia \\ ${ }^{3}$ Department of Clinical Pharmacy and Pharmacy Practice, School of Pharmacy, Eden University, Lusaka, Zambia \\ ${ }^{4}$ Department of Pharmacy, School of Medicine and Health Sciences, Mulungushi University, Kabwe, Zambia \\ Email: ^kampambamartin@gmail.com, *martin.kampamba@unza.zm
}

How to cite this paper: Kampamba, M., Maingaila, V., Akapelwa, T.M., Mudenda, S., Biete, L., Mufwambi, W., Banda, M., Phiri, M. and Hikaambo C.N. (2022) Assessment of Knowledge, Attitude and Practices towards the Disposal of Unused and Expired Medications among Students of Private Medical Universities in Lusaka, Zambia. Pharmacology \& Pharmacy, 13, 49-68. https://doi.org/10.4236/pp.2022.132004

Received: November 30, 2021

Accepted: February 13, 2022

Published: February 16, 2022

Copyright $\odot 2022$ by author(s) and Scientific Research Publishing Inc. This work is licensed under the Creative Commons Attribution International License (CC BY 4.0).

http://creativecommons.org/licenses/by/4.0/

\section{(c) (i) Open Access}

\begin{abstract}
Background: The disposal of unused and expired medications has been a concern in many countries in that, the pharmaceutical waste enters the ecosystem and eventually causes a negative impact on human health and environment. Aim: To assess the knowledge, attitude and disposal practices of unused and expired medicines by students in the private medical universities in Lusaka of Zambia. Method: A cross-sectional survey was conducted over a period of 8 weeks among 391 respondents from three private universities in Lusaka. Respondents were polled using semi structured questions that focused on their knowledge, attitudes, and disposal practices for unused and expired drugs. In order to analyze data, the statistical package for social sciences (SPSS) version 20 was utilized. Results: The mean age of the participants was 23 years (SD: \pm 3 ). Out of the 391 participants, 320 (81.8\%) knew about medicine waste and $391(100.0 \%)$ responded that unsafe disposal of unused and expired medicine poses a threat to human health and can harm the environment. The drug-take-back system was unknown to a vast percentage of the respondent 371 (94.9\%). The majority $274(70.1 \%)$ of respondents had unused medicine stored at home, with antibiotics 215 (56.0\%) and analgesia 111 (28.4\%) being the most prevalent types of drugs kept in the households. The most commonly used disposal practice for unused 126 (32.2\%) and expired medicines $274(70.1 \%)$ was throwing them in household garbage. Only 27 $(6.9 \%)$ and $30(7.7 \%)$ reported returning unused and expired medicines to the
\end{abstract}


nearest pharmacy respectively. The majority of respondents believed the risk stemmed from the presence of an undesired drug in the home, the potential for harm to children, a lack of proper information on safe disposal practices, and the necessity for a take-back program. Conclusions: The majority of the study participants used unsafe methods to dispose of unused and expired medicine. However, most of the participants acknowledged that unsafe disposal of unused and expired medicines is a public health problem and proposed the need to introduce drug take-back programs in the communities.

\section{Keywords}

Unused Medications, Expired Medications, Medicine Disposal, Medicine Waste

\section{Introduction}

A large number of pharmaceuticals and health care products are used every year for diagnosis, treatment, or prophylaxis of health conditions [1]. However, not all products that move into the hand of clients get consumed; massive portions remain unused or expire [1] [2]. Medicinal drugs may increase in households for a selection of motives which may include; improvement of the patient's medical condition, out-sized medication packages, death of the patient and change in prescription because of side effects or loss of therapeutic effect, bad adherence as the result of patients doubting the need for medication, worry of adverse results not forgetting bad reminiscence which also adds to medicinal drug waste [3] [4] [5].

Improper disposal system is a worldwide problem and occurs in both developing and developed countries, the problem being massive in developing countries though not well documented [6]. It results in issues such as treatment failure, health risk, medication resistance, patients' non-compliance, and overall decrease in the healthy lifestyles of population leading to increase in morbidity and mortality with additional unnecessary spending on medications and wastage of financial sources, by both the patient and health care system [7] [8].

Though there are options for disposing of unused drugs, many consumers keep drugs in their possession because of either them not wanting drugs to go to waste or not knowing how to properly dispose them [9] [10]. Keeping medications at home poses numerous dangers related to diversion, accidental overdose, and consumption of spoiled substances [9]. Storing of medicines at home can also promote self-medication which may also lead to insufficient dosage administration that can further promote drug resistance, medicine sharing with other members of family or neighbors [11] [12] [13]. Drugs stored at home may lose potency due to poor storage as a result of exposure to heat, light, humidity and air [14]. Expired drugs may pose toxicity risk due to the degradation effects that active substances undergo leading to the formation of toxic 
products [15].

The pharmaceutical wastes that have been detected throughout the environment were at least in some cases they have been discovered to have a negative effect [16]. In an associated press report in 2008, trace amounts of active pharmaceutical ingredients (APIs) were reported to have been found in the drinking water, a situation which posed an increased risk to human health. Some of the common drugs found in surface and drinking water include antibiotics, anticonvulsants, and artificial hormones [17].

Inappropriate disposal system contaminates surface bodies and drinking water and contributes to the development of antibiotics resistance or exposure of populations to an irritant or mutagenic anticancer drugs and the possible link between endocrine-disrupting compounds and failing fertility [14] [18]. Environmental exposure to pharmaceuticals could lead to a dangerous effect in particular on susceptible populations, including pregnant women, newborns, and children [19]. Consequently, the disposal practice of unused medicines has become a worldwide problem catching the attention of policymakers, health professionals, pharmaceutical companies, and the community in general [2].

The Study performed in distinct areas confirmed not only a different practice of disposal of unused medicinal but also respondents were now not completely aware of appropriate strategies. The studies conducted in Kenya, Nigeria, and Zambia have exposed throwing in garbage bins as the most preferred disposal method for unused pharmaceuticals, followed by flushing in the toilets [4] [20] [21]. In another study, the respondents stored the drug in their homes because they were not certain what to do with them while a few shared it with friends and families [22] [23]. These studies sincerely display that most of the respondents' lacked awareness of the proper methods of disposal of unused and expired drugs.

Even though different studies have been carried out in different parts of the world to reveal the degree of improper drug disposal, there was paucity of data on studies regarding disposal method practice of unused and expired medicines in private Universities of Zambia. Therefore, this study assessed the knowledge, attitudes, and disposal practices for unused and expired medications amongst students of the private university. Generally, this survey should serve as an indicator for environmental policymakers and the government of Zambia to take suitable measures regarding the disposal of unused and expired pharmaceuticals. Further research should be conducted on the recommended disposal practices and methods for various types of drugs.

\section{Materials and Methods}

\section{Study design, site and duration}

This was a cross-sectional study that was conducted at three major universities; Lusaka Apex Medical University (LAMU), Eden Medical University, and University of Lusaka (UNILUS) located in Lusaka, the capital city of Zambia. 
The study was conducted from the $1^{\text {st }}$ August to $30^{\text {th }}$ September 2021.

\section{Data collection procedure}

Data was gathered using a systematic self-administered questionnaire that was adapted from previous studies and tailored to our needs (Bashaar et al., 2017; Osei-Djarbeng et al., 2015). The three private institution were selected randomly among private universities in Lusaka. The questionnaire employed comprise four sections that cover participants' sociodemographic factors, knowledge, attitude, and practice regarding the disposal of unwanted and expired medicines. The questionnaire was tested in a pilot study with 20 pharmacy students who were chosen at random from another private institution which was not part of the study and questionnaire's Cronbach's alpha coefficient was 0.7 indicating that it could be used in this investigation. The strata and sample frame for the study, i.e. year of study and class list, were all used to randomly enroll the study participants.

\section{Sample size and sampling technique}

The sample size was calculated using slovin's formula since the study population size was known. $n=N / 1+N e^{2}$; Where $n=$ sample size, $N=$ study population size, $e=$ margin of error (5\%). Eden University had a student population of about 6000, LAMU had a student population of about 5000 and UNILUS had a student population of about 6500 . The ratio was 6:5:6.5 respectively. $n=N / 1+$ $N e^{2} ; N=6000+5000+6500=17,500$ students; $e=$ margin of error $(0.05) ; n=$ $17,500 / 1+17,500\left(0.05^{2}\right) ; n=391.0 ; n=391$ participants. The sample size for $\operatorname{EDEN}(6 / 17.5) \times 391=134.0=134$ participants, $\operatorname{LAMU}(5 / 17.5) \times 391=111.7=$ 112 participants and UNILUS $(6.5 / 17.5) \times 391=145.2=145$ participants.

\section{Data Analysis}

The collected data was checked for completeness, consistency, and accuracy before analyzing. Data from questionnaires was numerically coded to assist in analysis. Responses from closed-ended questions were assigned numerical values and analyzed quantitatively. The data was analysed using the statistical package of the social sciences (SPSS) version 22.0. Data was entered into the Microsoft Excel spread sheet before being exported to SPSS. A p $<0.05$ indicated statistical significance at a $95 \%$ confidence level.

\section{Ethical considerations}

To receive ethical permission, the research proposal was submitted to the University of Zambia's School of Health Sciences Research Ethics Committee (Ref202112030069). Potential participants gave written and verbal agreement after hearing about the study's goals and expected benefits. Their participation was entirely voluntary, and their privacy was guaranteed prior to completing the study. Potential participants were informed that there were no risks in participating in the study.

\section{Results}

Sociodemographic characteristics of the respondents 
All the approached 391 respondents agreed to participate in the study representing a 100\% response rate. Out of the 391 respondents, 209 (53.5\%) were males while 182 (46.5) were female. 371 (94.9\%) respondents were single. Participant distribution was as follows; UNILUS, 145 (37.1\%) had the most study participant, followed by EDEN, 134 (34.3\%), and LAMU, 112 (28.6\%). More than one-fourth $(110(28.1 \%))$ of the study participants were first year students (Table 1).

\section{Knowledge about Unused and Expired Medicine Disposal}

In this study, $320(81.8 \%)$ of the respondents knew about medicines waste. While 388 (99.2\%) never read medicine disposal instruction. 391 (100.0\%) of the respondents correctly responded that inappropriate disposal of unused/expired medicine can cause harm to the environment. 249 (63.7\%), 196 (50.1\%), and 87 (22.3\%) of the participants explained that inappropriate disposal of medicines can contaminate the environment, cause accidental swallow by children, and kill wildlife respectively. 354 (90.5\%) of respondents' suggested the provision of proper guidance on how to dispose of unused or expired medicines to the consumer could reduce or minimize the hazardous effect of unused/expired medication.

Table 1. Sociodemographic characteristics of participants in private academic institutions in Lusaka, $(n=391)$.

\begin{tabular}{|c|c|}
\hline Variable & Frequency (\%) \\
\hline \multicolumn{2}{|l|}{ Institution } \\
\hline Eden University & $134(34.3)$ \\
\hline Lusaka Apex Medical University & $112(28.6)$ \\
\hline University of Lusaka & $145(37.1)$ \\
\hline \multicolumn{2}{|l|}{ Age } \\
\hline mean $(\mathrm{SD})$ & $23( \pm 3)$ \\
\hline \multicolumn{2}{|l|}{ Gender } \\
\hline Male & $182(46.5)$ \\
\hline Female & $209(53.5)$ \\
\hline \multicolumn{2}{|l|}{ Marital Status } \\
\hline Married & $20(5.1)$ \\
\hline Unmarried & $371(94.9)$ \\
\hline \multicolumn{2}{|l|}{ Year of Study } \\
\hline $1^{\text {st }}$ & $110(28.1)$ \\
\hline $2^{\text {nd }}$ & $93(23.8)$ \\
\hline $3^{\text {rd }}$ & $83(21.2)$ \\
\hline $4^{\text {th }}$ & $41(10.5)$ \\
\hline $5^{\text {th }}$ & $64(16.4)$ \\
\hline
\end{tabular}


Pharmaceutical industries, mass-media, pharmacists and physicians, are responsible to create awareness to the public about the proper disposal of unused and expired medicines as reported by 227 (58.1\%) 132 (33.8\%), 130 (33.3\%), and 47 (12.0\%) of the respondents, respectively (Table 2 ).

\section{Respondents' Attitude towards Unused and Expired Medicine Disposal}

More than half (268 (68.5\%)) of the respondents "strongly agreed" about the potential risks related to having unused/expired medicines at home, and 217 (55.5\%) of them "strongly agreed" that children are more vulnerable to the risks associated with having unused and expired medicines in the household. Above half, $204(52.2 \%)$ and 171 (43.7\%), of the respondents "strongly agreed" and "agreed", respectively, on the need to initiate outreach and awareness creation programs on how to dispose of unused and expired medicines safely. Additionally, 152 (38.9\%) of the respondents "strongly agreed", and 183 (46.8\%) of them "agreed" that take-back programs of unused and expired medicines should be mandatory (Table 3).

\section{Disposal Practice of Unused and Expired Medicine}

$274(70.1 \%)$ of the respondents had kept unused or expired medicines in their households before. Improvement in medical condition 366 (93.6\%) followed by the change of medication by a prescriber $176(45.0 \%)$ was the main reason for having unused and expired medicine at home. 274 (70.1\%) of the participants indicated that they throw expired medicines, 27 (6.9\%) returned them while 157 (40.2\%) kept them. On unused medicines, 226 (32.2\%) throw them, 30 (7.7\%) return them, 45 (11.5\%) shared them with friends, and 274 (70.1\%) of the participants indicated that they keep unused medicines until they expire. The most commonly used disposal practice for unused medicines was throwing them in household garbage as reported by 126 (32.2\%) followed by flushing unused medications in the toilet/sink, 89 (22.8\%). Similarly, expired medicines were also disposed of by throwing away in household garbage and flushed in the toilet/sink as reported by $274(70.1 \%)$ and $203(51.9 \%)$ the respondents, respectively (Table 4).

The most commonly used classes of medicine kept in households as reported by the participants were antibiotics $215(56.0 \%)$ followed by analgesics 111 (28.4\%), then vitamin C 60 (15.4\%) and, (1.2\%), others as shown in Figure 1.

\section{Discussion}

Academic institutions contribute to the accumulation of an enormous amount of expired and unused medicines, and this can damage the environment as well as cause a public health problem (Kümmerer, 2010; Taras et al., 2014) [24] [25]. This can be minimized by implementing medicine disposal policy and guidelines and improving awareness of the public on appropriate medicine disposal methods and practices [26] [27] [28]. Therefore, the purpose of this study was to assess the knowledge, attitude, and practice of unused and expired medicines among students in private academic institutions in the Lusaka district of Zambia. In this study, $320(88.1 \%)$ of the respondents were aware of medication 
Table 2. Respondents' knowledge of unused and expired medicine disposal in private academic institutions in Lusaka, $(n=391)$.

\begin{tabular}{|c|c|}
\hline Variable & Frequency (\%) \\
\hline \multicolumn{2}{|l|}{ Do you know about medication waste? } \\
\hline No & $71(18.2)$ \\
\hline Yes & $320(81.8)$ \\
\hline \multicolumn{2}{|l|}{$\begin{array}{l}\text { If yes, which one of the following can be considered } \\
\text { as medicine wastes? }(n=320)^{*}\end{array}$} \\
\hline Expired medicines & $231(59.1)$ \\
\hline Leftover medicines due to some reasons & $46(11.8)$ \\
\hline Damaged medicines that cannot be used & $90(23.0)$ \\
\hline Once opened medication and beyond their recommended use date & $80(20.5)$ \\
\hline \multicolumn{2}{|l|}{ Do you ever read medicine disposal instructions? } \\
\hline No & $388(99.2)$ \\
\hline Yes & $3(0.8)$ \\
\hline \multicolumn{2}{|l|}{ Do you know about the "drug-take-back system"? } \\
\hline No & $371(94.9)$ \\
\hline Yes & $20(5.1)$ \\
\hline \multicolumn{2}{|l|}{$\begin{array}{l}\text { Do you know that misused/repeated change or failing } \\
\text { to complete antibiotics may cause drug resistance? }\end{array}$} \\
\hline No & $221(56.52)$ \\
\hline Yes & $170(43.5)$ \\
\hline \multicolumn{2}{|l|}{$\begin{array}{l}\text { Improper disposal of unused and expired medicines } \\
\text { can affect the environment and health }\end{array}$} \\
\hline No & $0.0(0.0)$ \\
\hline Yes & $391(100.0)$ \\
\hline \multicolumn{2}{|l|}{$\begin{array}{l}\text { What do you think is the possible harm associated with } \\
\text { inappropriate medicine disposal?* }\end{array}$} \\
\hline It can contaminate the environment & $249(63.7)$ \\
\hline It can kill wildlife & $87(22.3)$ \\
\hline Can cause accidental swallow by children & $196(50.1)$ \\
\hline \multicolumn{2}{|l|}{$\begin{array}{l}\text { How could the hazardous effect of unused and expired } \\
\text { medicines be minimized or controlled?* }\end{array}$} \\
\hline Providing proper guidance to the consumer & $354(90.5)$ \\
\hline $\begin{array}{l}\text { Prescribing in quantities and for a duration that ensures } \\
\text { patient compliance }\end{array}$ & $274(70.1)$ \\
\hline Lowering the quantities of prescribed medicine by a doctor & $297(76.0)$ \\
\hline Donating or sharing the unused medicines & $67(17.1)$ \\
\hline
\end{tabular}




\section{Continued}

\section{Who do you think is responsible for creation of public awareness about the proper disposal of unused and expired medicines?*}

$$
\begin{aligned}
& \text { Mass media } \\
& \text { Physician }
\end{aligned}
$$

Pharmacist

${ }^{*}$ Multiple response percent might exceed 100.

Table 3. Respondents' attitude towards unused and expired medicine disposal in private

\begin{tabular}{|c|c|c|c|c|c|}
\hline \multirow[b]{2}{*}{ Statement } & \multicolumn{5}{|c|}{ Responses } \\
\hline & $\begin{array}{l}\text { Strongly } \\
\text { agree } \\
f(\%)\end{array}$ & $\begin{array}{l}\text { Agree } \\
f(\%)\end{array}$ & $\begin{array}{c}\text { Neutral } \\
f(\%)\end{array}$ & $\begin{array}{c}\text { disagree } \\
f(\%)\end{array}$ & $\begin{array}{c}\text { Strongly } \\
\text { disagree } \\
f(\%)\end{array}$ \\
\hline $\begin{array}{l}\text { Unused and expired medicines } \\
\text { present potential risks at home }\end{array}$ & $\begin{array}{c}268 \\
(68.5)\end{array}$ & $\begin{array}{c}112 \\
(28.6)\end{array}$ & $\begin{array}{c}6 \\
(1.5)\end{array}$ & $\begin{array}{c}1 \\
(0.26)\end{array}$ & $\begin{array}{c}4 \\
(1.02)\end{array}$ \\
\hline $\begin{array}{l}\text { There is a lack of adequate } \\
\text { information on safe disposal } \\
\text { of unused medicine }\end{array}$ & $\begin{array}{c}152 \\
(38.9)\end{array}$ & $\begin{array}{c}198 \\
(50.6)\end{array}$ & $\begin{array}{c}12 \\
(3.1)\end{array}$ & $\begin{array}{c}24 \\
(6.1)\end{array}$ & $\begin{array}{c}5 \\
(1.3)\end{array}$ \\
\hline $\begin{array}{l}\text { Children are more vulnerable to the } \\
\text { risks of associated with unused and } \\
\text { expired household medicine }\end{array}$ & $\begin{array}{c}217 \\
(55.5)\end{array}$ & $\begin{array}{c}162 \\
(41.4)\end{array}$ & $\begin{array}{c}4 \\
(1.0)\end{array}$ & $\begin{array}{c}7 \\
(1.8)\end{array}$ & $\begin{array}{c}1 \\
(0.3)\end{array}$ \\
\hline $\begin{array}{l}\text { Doctors and health-care } \\
\text { professionals should provide advice } \\
\text { on safe disposal of unused and } \\
\text { expired household medicines }\end{array}$ & $\begin{array}{c}255 \\
(65.2)\end{array}$ & $\begin{array}{c}128 \\
(32.7)\end{array}$ & $\begin{array}{c}3 \\
(0.8)\end{array}$ & $\begin{array}{c}4 \\
(1.0)\end{array}$ & $\begin{array}{c}1 \\
(0.3)\end{array}$ \\
\hline $\begin{array}{l}\text { Take-back programs of unused } \\
\text { and expired medicines } \\
\text { should be mandatory }\end{array}$ & $\begin{array}{c}152 \\
(38.9)\end{array}$ & $\begin{array}{c}183 \\
(46.8)\end{array}$ & $\begin{array}{c}42 \\
(10.7)\end{array}$ & $\begin{array}{c}12 \\
(3.1)\end{array}$ & $\begin{array}{c}2 \\
(0.5)\end{array}$ \\
\hline $\begin{array}{l}\text { Outreach and awareness programs } \\
\text { about how to dispose of unused or } \\
\text { expired medicines should be initiated }\end{array}$ & $\begin{array}{c}204 \\
(52.2)\end{array}$ & $\begin{array}{c}171 \\
(43.7)\end{array}$ & $\begin{array}{c}11 \\
(2.8)\end{array}$ & $\begin{array}{c}3 \\
(0.8)\end{array}$ & $\begin{array}{c}2 \\
(0.5)\end{array}$ \\
\hline
\end{tabular}
academic institutions in Lusaka, $(n=391)$.

${ }^{\star} f$ indicates the frequency of responses.

Table 4. Respondents unused and expired medicine disposal practice in the private academic institution in Lusaka, $(n=391)$.

\begin{tabular}{cc}
\hline Questions & Frequency (\%) \\
\hline $\begin{array}{c}\text { Did any quantity of purchase medicine } \\
\text { remain unused at your home? }\end{array}$ & \\
No & $117(29.9)$ \\
Yes & $274(70.1)$ \\
\hline
\end{tabular}




\section{Continued}

If yes, what is the reason for having unused medication?

$$
(n=224)^{*}
$$

Improvement in medical condition

$366(93.6)$

Change of medication by prescriber

$176(45.0)$

Intolerable side effect

Keeping for future use

$148(37.9)$

What do you do with the unused medicines?*

Throw away in household garbage

Flush unused medications in toilet/sink

Keep at home until expired

Burn

Give to friends or relatives

Return back to pharmacy

I do not know what to do

What do you do with the expired medicines?*

Throw away in household garbage

Flush unused medications in the toilet/sink

Keep at home

$157(40.2)$

Burn

Give to friends or relatives

Return back to pharmacy

I do not know what to do

$21(5.4)$

*Multiple response percent might exceed 100.

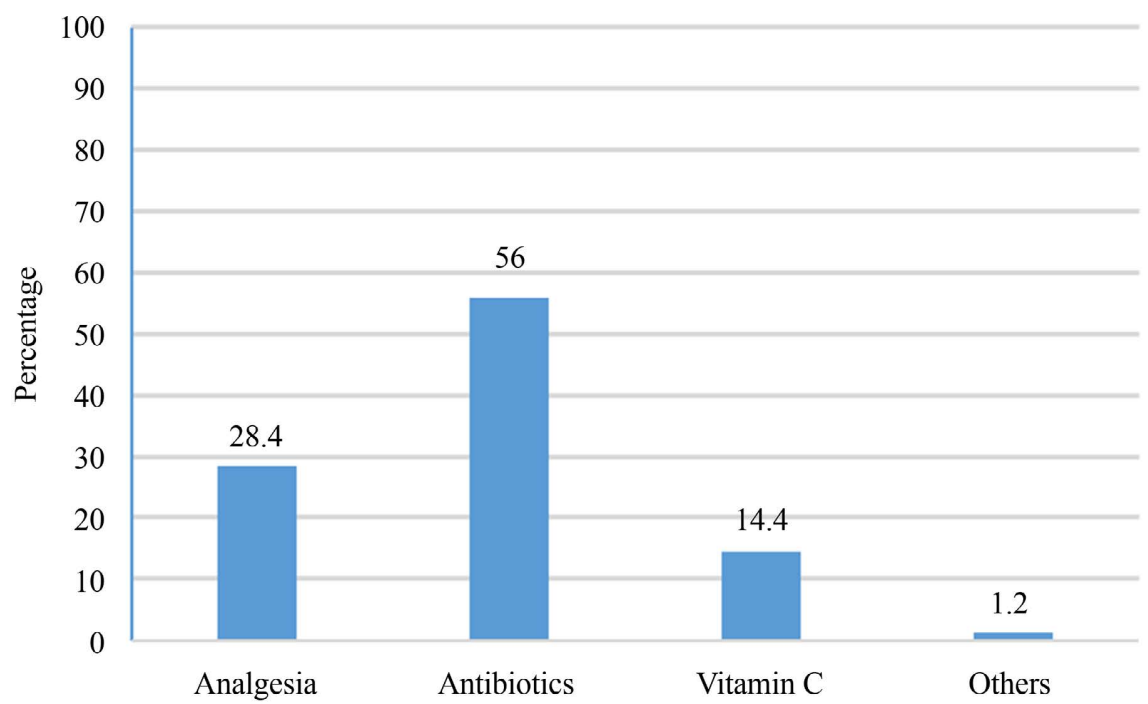

Figure 1. Class of medicines remained unused or expired among households. Others: Respiratory, Gastrointestinology, Central Nervous Drugs. 
waste and this is similar to the findings of a study that was conducted among the students of the International Islamic University, Malaysia [29]. However the findings of this study were higher than those reported from a study which was conducted among pharmacy students in Bangladesh in which only $36.2 \%$ of participants knew about medication waste [30]. Furthermore, the majority of the respondents 388 (99.2\%) denied having read any information on the safe disposal of unused. This finding is consistent with the findings of other studies [5] [30] [31]. This further indicates a need for student education on safe medicines waste disposal through the pharmaceutical industry, mass media, and health care professionals as suggested by respondents to improve consumers' awareness. The majority, $354(90.5 \%)$ of the study participants suggested providing proper guidance on how to dispose of unused and expired medicine to minimize the impacts of unused and expired medicines, followed by 297 (76.0\%) of the participants who suggested lowering the quantity of medicines prescribed to prevent the impact of unused and expired medicines. The finding is consistent with a previous study in Ethiopia [2].

Regarding the drug take-back program, only a few 20 (5.1\%) of the participants responded positively. These findings are similar to the findings of another study where only $3.7 \%$ of the respondents knew about the drug take-back program [30]. The low level of awareness regarding the drug take-back program seen in our study could be because of the lack of established drug take-back systems in our country. In this study, $391(100.0 \%)$ of the participants correctly understood the negative impacts of inappropriately disposing of unused and expired medicine to the environment. According to their understanding, it can cause environmental contamination, can kill wildlife and can cause accidental swallow by young children. These findings are consistent with the findings of other studies where more than half of the participants understood very well the negative impact of improper disposal of unused and expired medicines on the environment [2] [5] [32].

Additionally, $183(46.8 \%)$ and $152(38.9 \%)$ of the participants agreed and strongly agreed respectively that there is a need for the introduction of a drug take-back program to be collecting expired or unused medicines from the communities for safe disposal. Similar results were found in other studies conducted elsewhere (Kampamba et al., 2021a; Shivaraju \& Gangadhar, 2017) [5] [33]. A drug take-back program provides an appropriate disposal method and may lessen the likelihood of expired and unused medicines going into the environment and therefore preventing environmental pollution if implemented by the government [34].

In this study, 198 (50.6\%) of the participants agreed that there was a lack of adequate information on the safe disposal practice of unused and expired medicines. Above half, 204 (52.2\%) of the participants agreed on the need to have an awareness creation program on how to dispose of unused and expired medicines properly. Additionally, the participants suggested that the awareness of proper disposal methods of unused drugs should be mainly done through the pharma- 
ceutical industry 227 (58.1\%), mass media 132 (33.8\%), pharmacists 130 (33.3\%), and physicians $47(12.0 \%)$. This finding is highlighted by other studies $(2,[35])$. According to this study, health care professionals were not informing their patients regarding proper disposal of unused and expired medicines, and the majority of the participants were demanding further awareness creation programs. This all indicates the need to implement an awareness creation campaign through appropriate mediums to promote proper medicine disposal practices.

This study established 274 (70.1) of the respondents had unused or expired medicines in their household. These findings are consistent with other studies. Concerning the risks of storing unused and expired medicines in their homes, $268(68.5 \%)$ of participants strongly agreed that children are more susceptible to the risks related to unused and expired household medicines. The high level of unused and expired household medicine storage practice can be a source of accidental poisoning by young children is common and therefore, the need to appropriately store and safely dispose of unused and expired medicines [36]. The most common classes of medicine kept in households as reported by the participants were antibiotics, 215 (56.0\%) followed by analgesics, $111(28.4 \%)$ and vitamins, 60 (15.4\%). This finding is consistent with the findings of other studies. Reasons for having unused or expired medicines were mainly due to improvement in medical condition 366 (93.6\%), followed by the change of medicines by the prescriber, 176 (45.0\%), keeping for future use 148 (37.9\%), and intolerable medicine side effect, 28 (7.2) were the most commonly mentioned reasons for having leftover medicines. This was in agreement with other studies [32] [37].

In the present study, throwing away the medicines in household garbage and flushing in the toilet/sink were the most commonly preferred disposal practices for both unused and expired medicines. The finding is in agreement with studies done elsewhere [33] [38]. But in contrast with a study done in Nepal among paramedical students where a relatively low proportion of the participants threw and kept expired and unused medicines [39]. The difference in the findings could be attributed to the nature of participants as all the participants in Nepal were doing health courses and likely to receive appropriate information during their training regarding disposal of unused and expired medicines, unlike our study which consisted of a mixture of students doing health courses and non-health courses. In this study, burning leftover medicines were the other means of disposing for both unused and expired household medicines as reported by 79 $(20.2 \%)$ of the respondents. But very few, 30 (7.7\%) of participants were reported returning unused and expired medicines to the pharmacy. This is in agreement with a previous study from Ethiopia [2]. The reason might be due to a lack of awareness on how to appropriately dispose of unused/expired medicines. But other studies were conducted in Sweden, Portugal, New Zealand, and the United States of America where a majority of the participants returned unwanted medication to the pharmacy [40] [41] [42]. The disparity could be attributable to the existence of mechanisms in Sweden, Portugal, New Zealand, and the United States of America that encourage correct disposal of leftover medicine. 
Environmental pollution with drugs such as antimicrobial agents has been reported to be a common cause of antimicrobial resistance (AMR) in the environment. Evidence has shown that the unusual disposal of unused and expired drugs such as antibiotics in the environment can contribute to increase AMR [5] [22]. AMR has several penalties including increased utilization of resources, economic and clinical burdens, and increased morbidity and mortality [43] [44]. In the future, all necessary strategies and ethical approaches must be put in place to curb AMR [45]. We need to conserve our environment by avoiding the disposal of unused and expired drugs in the environment.

\section{Study limitation}

Because of the nature of our research, we may have run into certain constraints. Cross-sectional studies are predisposed to social desirability bias by their very nature. However, the study employed self-administered questionnaire that was then returned in an envelope. The structure of our study could possibly lead to recollection bias, which could impair genuine knowledge and practices about expired/unused drugs.

\section{Conclusion}

This study revealed that although the majority of the participants had a positive attitude towards safe disposal methods, participants from the three private Universities had a low level of knowledge on safe disposal methods of expired and unused medicines. The study also revealed that the participants practiced discouraged methods of disposing of unused and expired medicines. Therefore, there is an immense need to create awareness campaigns and drug take-back programs to enhance the knowledge and improve the attitude of Zambians towards safe and appropriate methods of unused and expired medicine are disposal.

\section{Conflicts of Interest}

There are no conflicts of interest.

\section{References}

[1] Bound, J.P. and Voulvoulis, N. (2005) Household Disposal of Pharmaceuticals as a Pathway for Aquatic Contamination in the United Kingdom. Environmental Health Perspectives, 113, 1705-1711. https://doi.org/10.1289/ehp.8315

[2] Ayele, Y. and Mamu, M. (2018) Assessment of Knowledge, Attitude and Practice towards Disposal of Unused and Expired Pharmaceuticals among Community in Harar City, Eastern Ethiopia. Journal of Pharmaceutical Policy and Practice, 11, 1-7. https://doi.org/10.1186/s40545-018-0155-9

[3] Al-Naggar, R.A. and Alareefi, A. (2010) Patients' Opinion and Practice toward Unused Medication Disposal in Malaysia: A Qualitative Study. Thai Journal of Pharmaceutical Sciences, 34, 117-123.

[4] Kampamba, M., Nyirenda, M., Hatwiko, H., Kampamba, D. and Hikaambo, C.N. (2020) Assessment of Household Knowledge, Attitude and Practices on Disposal Methods of Expired and Unused Medicines among Residents of Lusaka City, Zambia. African Journal of Pharmacy and Pharmacology, 14, 221-228. 
https://doi.org/10.5897/AJPP2020.5165

[5] Kampamba, M., Cheela, T., Hikaambo, C.N., Mudenda, S., Saini, K. and Chabalenge, B. (2021) Knowledge, Attitude, and Practices on Disposal Methods of Expired and Unused Medicines among Students in Public Academic Institutions in Lusaka, Zambia. International Journal of Basic \& Clinical Pharmacology, 10, 774. https://doi.org/10.18203/2319-2003.ijbcp20212371

[6] Fernandes, M.R., Figueiredo, R.C., Silva, L., Rocha, R.S. and Baldoni, A.O. (2020) Storage and Disposal of Expired Medicines in Home Pharmacies: Emerging Public Health Problems. Einstein (São Paulo), 18, eAO5066. https://doi.org/10.31744/einstein_journal/2020AO5066

[7] Ruhoy, I.S. and Daughton, C.G. (2008) Beyond the Medicine Cabinet: An Analysis of Where and Why Medications Accumulate. Environment International, 34, 1157 1169. https://doi.org/10.1016/j.envint.2008.05.002

[8] Gracia-Vásquez, S.L., Ramírez-Lara, E., Camacho-Mora, I.A., Cantú-Cárdenas, L.G., Gracia-Vásquez, Y.A., Esquivel-Ferriño, P.C., et al. (2015) An Analysis of Unused and Expired Medications in Mexican Households. International Journal of Clinical Pharmacy, 37, 121-126. https://doi.org/10.1007/s11096-014-0048-1

[9] Makki, M., Hassali, M.A., Awaisu, A. and Hashmi, F. (2019) The Prevalence of Unused Medications in Homes. Pharmacy, 7, 61. https://doi.org/10.3390/pharmacy7020061

[10] Marwa, K.J., Mcharo, G., Mwita, S., Katabalo, D., Ruganuza, D. and Kapesa, A. (2021) Disposal Practices of Expired and Unused Medications among Households in Mwanza, Tanzania. PLoS ONE, 16, e0246418.

https://doi.org/10.1371/journal.pone.0246418

[11] Foroutan, B. and Foroutan, R. (2014) Household Storage of Medicines and SelfMedication Practices in South-East Islamic Republic of Iran. EMHJ-Eastern Mediterranean Health Journal, 20, 547-553. https://doi.org/10.26719/2014.20.9.547

[12] Jassim, A.-M. (2010) In-Home Drug Storage and Self-Medication with Antimicrobial Drugs in Basrah, Iraq. Oman Medical Journal, 25, 79.

https://doi.org/10.5001/omj.2010.25

[13] Kampamba, M., Demba, F., Mudenda, S., Mufwambi, W., Zingani, E., Chabala, F.W., et al. (2021) Medication Administration Omission Errors: Frequency and Their Causes during Medication Administration Process at Ndola Teaching Hospital in Zambia. African Journal of Pharmacy and Pharmacology, 15, 174-182. https://doi.org/10.5897/AJPP2021.5264

[14] Atinafu, T., Takele, A., Kassie, A., Yehualaw, A., Tesfaw, G., Desseno, T., et al. (2014) Unused Medications Disposal Practice: The Case of Patients Visiting University of Gondar Specialized Teaching Hospital, Gondar, Ethiopia. International Journal of Pharmaceutical Sciences and Research, 5, 999-1005.

[15] Parezanović, G.Š., Lalic-Popovic, M., Golocorbin-Kon, S., Vasovic, V., Milijašević, B., Al-Salami, H., et al. (2019) Environmental Transformation of Pharmaceutical Formulations: A Scientific Review. Archives of Environmental Contamination and Toxicology, 77, 155-161. https://doi.org/10.1007/s00244-019-00630-z

[16] Kümmerer, K. (2009) The Presence of Pharmaceuticals in the Environment Due to Human Use-Present Knowledge and Future Challenges. Journal of Environmental Management, 90, 2354-2366. https://doi.org/10.1016/j.jenvman.2009.01.023

[17] Talerico, D.D. (2012) Pharmaceutical [IE Pharmaceutical] Pollution Prevention: An Examination of Medication Disposal Systems in Washington, Maine, New York, the San Francisco Bay Area, and Rhode Island: Program in Environmental Studies, Brown 
University.

[18] Costanzo, S.D., Murby, J. and Bates, J. (2005) Ecosystem Response to Antibiotics Entering the Aquatic Environment. Marine Pollution Bulletin, 51, 218-223.

https://doi.org/10.1016/j.marpolbul.2004.10.038

[19] Daughton, C.G. (2003) Cradle-to-Cradle Stewardship of Drugs for Minimizing Their Environmental Disposition While Promoting Human Health. II. Drug Disposal, Waste Reduction, and Future Directions. Environmental Health Perspectives, 111, 775-785. https://doi.org/10.1289/ehp.5948

[20] Angi'enda, S.A. and Bukachi, S.A. (2016) Household Knowledge and Perceptions on Disposal Practices of Unused Medicines in Kenya. Journal of Anthropological Archaeology, 4, 1-20. https://doi.org/10.15640/jaa.v4n2a1

[21] Auta, A., Omale, S., Shalkur, D. and Abiodun, A.H. (2011) Unused Medicines in Nigerian Households: Types and Disposal Practices. Journal of Pharmacology \& Pharmacotherapeutics, 2, 195-196. https://doi.org/10.4103/0976-500X.83290

[22] Bashaar, M., Thawani, V., Hassali, M.A. and Saleem, F. (2017) Disposal Practices of Unused and Expired Pharmaceuticals among General Public in Kabul. BMC Public Health, 17, 45. https://doi.org/10.1186/s12889-016-3975-Z

[23] Osei-Djarbeng, S.N., Larbi, G.O., Abdul-Rahman, R., Osei-Asante, S. and OwusuAntwi, R. (2015) Household Acquisition of Medicines and Disposal of Expired and Unused Medicines at Two Suburbs (Bohyen and Kaase) in Kumasi-Ghana. The Pharma Innovation, 4, 85.

[24] Kümmerer, K. (2010) Pharmaceuticals in the Environment. Annual Review of Environment and Resources, 35, 57-75.

https://doi.org/10.1146/annurev-environ-052809-161223

[25] Taras, H., Haste, N.M., Berry, A.T., Tran, J. and Singh, R.F. (2014) Medications at School: Disposing of Pharmaceutical Waste. Journal of School Health, 84, 160-167. https://doi.org/10.1111/josh.12132

[26] Barnett-Itzhaki, Z., Berman, T., Grotto, I. and Schwartzberg, E. (2016) Household Medical Waste Disposal Policy in Israel. Israel Journal of Health Policy Research, 5, 1-8. https://doi.org/10.1186/s13584-016-0108-1

[27] Bataduwaarachchi, V.R. and Weeraratne, C.L. (2016) Global Medication Waste Management Practices: Challenges and Opportunities in Developing Countries. International Journal of Basic and Clinical Pharmacology, 5, 2290-2294.

[28] Dias-Ferreira, C., Valente, S. and Vaz, J. (2016) Practices of Pharmaceutical Waste Generation and Discarding in Households across Portugal. Waste Management \& Research, 34, 1006-1013. https://doi.org/10.1177/0734242X16639388

[29] Azad, M.A.K., Ansary, M.R.H., Akhter, A., Al-Mamun, S., Uddin, M. and Rahman, M. (2012) Disposal Practice for Unused Medications among the Students of the International Islamic University Malaysia. Journal of Applied Pharmaceutical Science, 2, 101-106. https://doi.org/10.7324/JAPS.2012.2712

[30] Iabu, K., Al-Mamun, M., Harun, M. and Sikder, K. (2013) Knowledge, Awareness and Disposal Practice for Unused Medications among the Students of the Private University of Bangladesh. Journal of Biomedical and Pharmaceutical Research, 2, 26-33.

[31] Gidey, M.T., Birhanu, A.H., Tsadik, A.G., Welie, A.G. and Assefa, B.T. (2020) Knowledge, Attitude, and Practice of Unused and Expired Medication Disposal among Patients Visiting Ayder Comprehensive Specialized Hospital. BioMed Research International, 2020, Article ID: 9538127. https://doi.org/10.1155/2020/9538127 
[32] Kristina, S.A. (2018) A Survey on Medicine Disposal Practice among Households in Yogyakarta. Asian Journal of Pharmaceutics, 12, S955.

[33] Shivaraju, P.T. and Gangadhar, M. (2017) Knowledge and Awareness of Disposal of Unused and Expired Medications among Medical Undergraduates of a Tertiary Care Teaching Hospital at BG Nagar: A Cross-Sectional Observational Study. National Journal of Physiology, Pharmacy and Pharmacology, 7, 1268-1273. https://doi.org/10.5455/njppp.2018.8.0727006072017

[34] Yanovitzky, I. (2016) The American Medicine Chest Challenge: Evaluation of a Drug Take-Back and Disposal Campaign. Journal of Studies on Alcohol and Drugs, 77, 549-555. https://doi.org/10.15288/jsad.2016.77.549

[35] Sonowal, S., Desai, C., Kapadia, J.D. and Desai, M.K. (2016) A Survey of Knowledge, Attitude, and Practice of Consumers at a Tertiary Care Hospital Regarding the Disposal of Unused Medicines. Journal of Basic and Clinical Pharmacy, 8, 4.

[36] Anderson, M., Hawkins, L., Eddleston, M., Thompson, J.P., Vale, J.A. and Thomas, S.H. (2016) Severe and Fatal Pharmaceutical Poisoning in Young Children in the UK. Archives of Disease in Childhood, 101, 653-656. https://doi.org/10.1136/archdischild-2015-309921

[37] Gupta, R., Gupta, B.M. and Gupta, A. (2019) A Study on Awareness Regarding Disposal of Unused Medicines among Consumers at a Tertiary Care Teaching Hospital of North India. International Journal of Advances in Medicine, 6, 91-95. https://doi.org/10.18203/2349-3933.ijam20190111

[38] Azmi Hassali, M. and Shakeel, S. (2020) Unused and Expired Medications Disposal Practices among the General Public in Selangor, Malaysia. Pharmacy, 8, 196. https://doi.org/10.3390/pharmacy8040196

[39] Nepal, S., Giri, A., Shastry, C., Chand, S., Aryal, S., Khanal, P., et al. (2020) Outdated and Unused Medicines Disposal Practice among the Undergraduate Paramedical Students-A Pharmacist's Intervention. Le Pharmacien Hospitalier et Clinicien, 55, 327-333. https://doi.org/10.1016/j.phclin.2020.05.003

[40] Braund, R., Peake, B.M. and Shieffelbien, L. (2009) Disposal Practices for Unused Medications in New Zealand. Environment International, 35, 952-955.

https://doi.org/10.1016/j.envint.2009.04.003

[41] Kozak, M.A., Melton, J.R., Gernant, S.A. and Snyder, M.E. (2016) A Needs Assessment of Unused and Expired Medication Disposal Practices: A Study from the Medication Safety Research Network of Indiana. Research in Social and Administrative Pharmacy, 12, 336-340. https://doi.org/10.1016/j.sapharm.2015.05.013

[42] Persson, M., Sabelström, E. and Gunnarsson, B. (2009) Handling of Unused Prescription Drugs-Knowledge, Behaviour and Attitude among Swedish People. Environment International, 35, 771-774. https://doi.org/10.1016/j.envint.2008.10.002

[43] Kalonga, J., Hangoma, J., Banda, M., Munkombwe, D. and Mudenda, S. (2020) Antibiotic Prescribing Patterns in Paediatric Patients at Levy Mwanawasa University Teaching Hospital in Lusaka, Zambia. International Journal of Pharmaceutics \& Pharmacology, 4, Article No. 138. https://doi.org/10.31531/2581-3080.1000138

[44] Kampamba, M., Mulolo, S., Phiri, M., Chulu, M.C., Mufwambi, W., Mudenda, S., et al. (2021) Medication Omissions in the First 48 Hours after Admission: Failure in Prescribed Medicines Reaching In-Patients in Paediatrics Wards at the University Teaching Hospitals, Children's Hospital in Lusaka, Zambia. International Journal of Basic \& Clinical Pharmacology, 10, 1324-1329. https://doi.org/10.18203/2319-2003.ijbcp20214497

[45] Parsonage, B., Hagglund, P.K., Keogh, L., Wheelhouse, N., Brown, R.E. and Dancer, 
S.J. (2017) Control of Antimicrobial Resistance Requires an Ethical Approach. Frontiers in Microbiology, 8, Article No. 2124.

https://doi.org/10.3389/fmicb.2017.02124 


\section{Questionnaire}

SECTION A: Socio-demographic characteristics of the participant. Tick in a box on what is applicable to you.

1) Institution Name
a) LAMU
b) UNILAS
c) EDEN
2) Gender
a) Male
b) Female
3) Age (in years)
4) Marital Status
a) Married [ ]
b) Unmarried [ ]
5) Year of Study [ ]

SECTION B: Assessment of Knowledge on disposal methods of expired and unused medicines. Tick on an appropriate box for your answer in section $B, C$ and $D$.

1) Do you know about medication waste?
a) Yes [ ]

b) No []

2) If yes, which one of the following can be considered as medicine wastes (multiple answers allowed)?
a) Expired medicines [ ]
b) Leftover medicines due to some reasons [ ]
c) Damaged medicines that cannot be used [ ]
d) Once opened medication and beyond their recommended use date [ ]
3) Do you ever read medicines disposal instructions?
a) No [ ]
b) Yes [ ]
4) Do you know about "drug-take-back system"?
a) No
b) Yes
5) Do you know that misused/repeated change or failing to complete antibio- tics may cause drug resistance?
a) No
b) Yes
6) Improper disposal of unused and expired medicines can affect the environment and health.
a) No
b) Yes
7) What do you think is the possible harm associated within appropriate medi- cine disposal (multiple answers allowed)? 
a) It can contaminate the environment [ ]

b) It can kill wildlife [ ]

c) Can cause accidental swallow by children [ ]

8) How could be hazardous effect of unused and expired medicines minimized or controlled (multiple answers allowed)?

a) Providing proper guidance to the consumer [ ]

b) Prescribing in quantities and for duration that ensure patient compliance [ ]

c) Lowering the number of prescribed medicine by doctor [ ]

d) Donating or sharing the unused medicines [ ]

e) Others (specify) [ ]

9) Who do you think is responsible to create public awareness about proper disposal of unused and expired medicines (multiple answers allowed)?
a) Mass media [ ]
b) Physician [ ]
c) Pharmacists [ ]
d) The pharmaceutical industry [ ]

SECTION C: Assessment of attitude on disposal methods of expired and unused medicines

10) Unused and expired medicines present potential risks at home.

a) strongly agreed [ ]

b) agree [ ]

c) I don't know [ ]

d) Disagree [ ]

e) Strongly disagree [ ]

11) There is lack of adequate information on safe disposal of unused medicine.
a) strongly agreed [ ]
b) agree [ ]
c) I don't know [ ]
d) Disagree [ ]
e) Strongly disagree [ ]

12) Children are more vulnerable to the risks of associated with unused and expired household medicines.
a) strongly agreed [ ]
b) agree [ ]
c) I don't know [ ]
d) Disagree [ ]
e) Strongly disagree [ ]

13) Doctors and healthcare professionals should provide advice on safe disposal of unused and expired household medicine.
a) strongly agreed [ ]
b) agree [ ] 


\section{c) I don't know [ ] \\ d) Disagree [ ] \\ e) Strongly disagree [ ]}

14) Take-back programs of unused and expired medicines should be mandatory.
a) strongly agreed [ ]
b) agree [ ]
c) I don't know [ ]
d) Disagree [ ]
e) Strongly disagree [ ]

15) Outreach and awareness programs about how to dispose unused or expired medicines should be initiated.
a) strongly agreed [ ]
b) agree [ ]
c) I don't know [ ]
d) Disagree [ ]
e) Strongly disagree [ ]

SECTION D: Determination of disposal methods of expired and unused medicines.

16) Did any quantity of purchased or dispensed medicine remain unused at your home?

a) Yes [ ]

b) No [ ]

17) If yes, what is the reason for having unused medication (multiple answers allowed)?
a) Improvement in medical condition [ ]
b) Change of medication by prescriber [ ]
c) Experiencing side effects [ ]
d) Keeping for future use [ ]
e) Forgetting [ ]

18) What type of medicines remained unused at home?
a) Analgesics
b) Antibiotics
c) Antihypertensive
d) Antidiabetics
e) Others (specify)

19) What do you do with unused medicines?

a) Throw away in household garbage [ ]

b) Flush unused medications in toilet/sink [ ]

c) Keep at home until expired [ ]

d) Burn 122 [ ]

e) Give to friends or relatives [ ]

f) Return back to pharmacy [ ] 
g) I do not know what to do [ ]

20) What do you do with the expired medicines?

a) Throw away in household garbage [ ]

b) Flush unused medications in toilet/sink [ ]

c) Keep at home [ ]

d) Burn [ ]

e) Give to friends or relatives [ ]

f) Return back to pharmacy [ ]

g) I do not know what to do [ ] 